in the waters of Iceland and the Færöes, the investigations will have a more official character, being carried out at the expense of the Danish Government and as part of the international scheme of work. The second part of the cruise will set out in the beginning of July from some English port. The expenses of this portion of the expedition will be defrayed partly by the Carlsberg Institution of Copenhagen, which does so much for the promotion of science in Denmark, partly from private sources.

Both in the Atlantic and Mediterranean the expedition will work over waters which have been already, for a great part, investigated by the Thor. It is not proposed to devote much time to the Atlantic region south of Ireland, and there is the less reason for doing so as previous workers, especially the Prince of Monaco, Schmidt, and the Irish investigators, have already done so much there. Nevertheless, a series of deep-sea hydrographical observations from the south of Ireland to the coast of Morocco, continuous with similar series from Iceland to Ireland and through the Mediterranean, will be of extreme interest, both in biological matters and as a further contribution towards understanding the circulation of the waters of the Atlantic and the adjacent seas.

In the Mediterranean, on the other hand, the hydrographical and biological conditions are only imperfectly understood. As is well known, the Mediterranean is an almost completely land-locked and independent ocean, with an average depth of more than rooo fathoms, descending at places to 2000 fathoms. This huge basin is connected with the Atlantic at the Straits of Gibraltar by a narrow sill or threshold, which is only 200 fathoms deep. Any mixing of the Atlantic water with the Mediterranean waier can therefore only proceed on the surface, and the renewal of the deeper layers, which is necessary for the development of an abyssal life, and which actually does take place, can only be due to the conditions, evaporation, convection currents, but mostly wind influence, prevailins in the Mediterranean itself. On the other hand, it seems certain from earlier investigations that the deep water of the Mediterranean, which is much more saline than the Atlantic, occasionally or normally wells up over the threshold at the Straits and flows out into the Atlantic as a deep-water current with a northerly direction. A further interesting topographical feature of the Mediterranean is that it is divided into two deep-water basins by a submarine ridge, which stretches across between Sicily and Tunis, and is only about 150 fathoms deep. The circulation of the waters within the two deep basins west and east of this ridge must therefore be for the most part independent. The determination of the character of the water in the two basins, in all layers from the surface to the bottom, promises results of more than usual interest.

The hydrographical observations will be of two kinds, physical and chemical. The temperature and salinity will be determined, as also the direction and strength of the currents, in all depths from surface to bottom, in accordance with the most modern methods employed by the international investigations. Entirely new methods have also been recently worked out by Danish men of science at the Carlsberg Laboratory in Copenhagen for the determination of the chemical composition of sea water, for example, the dissolved gases $\left(\mathrm{O}, \mathrm{N}, \mathrm{CO}_{2}\right)$ and the alkalinity (concentration of $\mathrm{H}$-ions). It is probable that these new methods will throw fresh light upon the factors determining the differences in the occurrence and appearance of the organic life at different depths and in different waters, differences which the salinity and temperature by themselves cannot explain. It is obvious that the waters mentioned in the Atlantic and Mediterranean offer exceptional opportunities for such an investigation.

On the biological side, the investigations will be on the lines followed by the International Council for the Study of the Sea, and will be directed, in the first place, to the elucidation of the life-histories and biological conditions of the principal fishes. The advantage of making investigations over a wide area, as from Iceland to Morocco and the Mediterranean, is just that the differences in the physical conditions are marked on a large scale, and can be connected directly as cause to effect with the very distinct differences in the occurrences and biological phenomena of all organisms, from the floating plankton to the fishes. One of the most interesting problems here will thus be to determine the relation between the Atlantic and Mediterranean faunas, how far the latter is dependent, if at all, on the former, and the differences in the abyssa life of the two regions, all in connection with the physical and chemical differences.

\section{A NEW AMPEREMETER.}

A NEW aperiodic millivolt and amperemeter for continuous and alternating currents has been brought to our notice by Messrs. Isenthal and Co. The operation of the instrument is based on methods already described by Drude and Klemencic, in which the current to be measured is caused to heat up thermojunctions, thus setting up indirectly a current which actuates the movement of the instrument. The novelty in the present instrument consists in the arrangement adopted for combining the action of a number of thermojunctions in such a manner that thermocurrents are produced of sufficient magnitude to deflect an ordinary pivoted moving-coil instrument.

The thermocouples are placed in the four arms of a Wheatstone's bridge, the movement being connected to two opposite corners of the bridge, and the leads carrying the current that is to be measured to the remaining corners. The polarities of the thermocouples are so chosen that when the bridge is warmed up by the passage of a current the electromotive forces set up in the four arms conspire so as to send a current through the movement. The arms of the bridge are adjusted so that the thermoelectric current passes through the movement without entering the external circuit, and the current from the external source passes through the thermocouples without affecting the galvanometer.

As the deflections of the instrument depend on the heating effect of the current to be measured, it should give correct readings for direct current or alternating current of any wave-shape or frequency. It seems that sources of error might be introduced by Peltier effects and changes of temperature of the surroundings, and it would be interesting to learn to what extent such errors are appreciable, and in what manner they have been compensated for.

The sensitiveness of the meter is 225 millivolts with a current of $\mathrm{I}$ ampere, and its range as an amperemeter can be increased to any extent by the use of shunts.

\section{GEOLOGY OF THE LONDON DISTRICT.}

THE Geological Survey cannot well be charged with neglect of London, except in the matter of six-inch maps, a want that will probably be soon seen to. From I864 to 1906 various memoirs were issued which deal, though sometimes only partially, with the geology of London and the neighbourhood. Two of these, however, treat of the whole district and the whole of its geology, and now we have a third, in which the results reached by many workers are given up to date.

This memoir may be said to have been done by $\mathrm{Mr}$. Woodward to celebrate his retirement from office, more than a year ago, and a remarkably good celebration it is. From its very low price it is within the reach of all students, and we may hope that its author may live to edit many editions.

The area described is that covered by the lately published four sheets of the new geological map of London, some errors in which are duly noted on p. v. After a general account of the area, five pages are given to an account of the various beds beneath the Chalk, which do not come to the surface here, their presence underground having been proved only by borings. These consist of Devonian rocks, at the base, Red Rocks of doubtful age,

1 Memoirs of the Geological Survey. The Geology of the London District. By, H. B. Woodward, F.R.S. Pp. viii $+142+$ plate. (London:
His Majesty's Stationery Office : E. Stanford: Edinburgh: W. and A. K. Johnston, Ltd. Dublin: Hodges, Figgis and Co., 19c9. Price is.

NO. 2 I 18 , VOL. $\left.\&_{3}\right]$ 
Great Oolite beds, possibly some Lower Greensand, and in every boring Gault and Upper Greensand. The omissions in the series are notable; we have no certain Carboniferous rocks, only a possibility of Trias, no Lias, only one division of the great Jurassic series, and no Wealden beds, a perfect succession being reached only with the Gault.

To the description of the Chalk nine pages are given, and as the Middle and Lower divisions are found only underground, in borings, these are concerned chiefly with the Upper Chalk. The zones of the whole formation, with the distinctive fossils, are noted.

The Eocene Tertiaries, which form so large a part of the district, take twenty-five pages for their description, which are followed by four pages on faults and disturbances, after which the various members of the great Drift series, so greatly in evidence in the district, are described at some length, the Older Drifts with eleven pages to their credit, the Glacial (and allied) Drift with thirteen, whilst the description of the Valley Drifts, with their flint implements, extends to twenty-three pages.

The stratigraphic series ends with Recent beds, the Alluvium of the rivers being described in eight pages, after which the remaining ten pages of the chapter treat of some other matters, namely, a description of the Thames, its tributaries and its buried rivers, floods, fords, old trackways, a short account of the growth of London, and a summary of the physical changes in the district from the time of the deposit of the Chalk to the formation of the Alluvium.

The question of water-supply from the various beds is discussed in nine pages, and various other economic questions in other ten, which conclude the work, except for the lengthy index.

The plate is a contour-map of the district, with a geologic section from the valley of the Gade, on the northwest, to beyond that of the Darent, on the south-east.

At the end of the various subjects a list of the chief works relating to each is given, and this will be of much use to those who want further detail. But with this memoir in hand nearly everyone may know as much about the geology of London, using that name in a wide sense, as he needs to know.

\section{ECONOMIC ENTOMOLOGY.}

I $\mathrm{N}$ the last number of the Journal of Economic Biology (vol. v., pp. 9-17) Mr. W. E. Collinge gives some interesting notes on the form of the egg of the horse botfly (Gastrophilus equi), its attachment to the horse's hair, and the method of its hatching. The narrow end of the subconical egg is not simply glued to the hair; it clasps the hair by means of a pair of ridges or lips, so that the area of attachment is like that of the ox warble-fly (Hypoderma bovis), only less specialised. With regard to the mode of hatching, Mr. Collinge's observations and experiments confirm, in the main, the statements of Bracy Clark and Osborn. He found that the eggs were most readily induced to hatch, by the application of moisture, from sixteen to twenty days after hatching; none could be induced to hatch after thirty-six days.

Mr. R. Newstead describes in the same part (pp. 18-22) a couple of new species of Coccidæ from the Congo, which live as guests of ants (Cremastogaster and Sima) in their nests in the hollow shoots of plants. It is very rarely that irsects of this family are found in the hollow stems of their food-plants. One specimen contained a minute lepidopterous larva which had partly destroyed its host.

It is well known that economic entomologists in North America are much troubled by the ravages of insects purposely or accidentally imported into their country from Europe; one of the most famous of these is the gipsy moth (Porthetria dispar). Dr. L. O. Howard has lately (U.S. Dept. Agric. Bur. Entom., Tech. Ser., 19) described some parasites reared from the eggs of this insect. It is remarkable that the parasites - various species of minute Hymenoptera-all come from Hungary, Russia, and Japan. From Gipsy-moth eggs imported from western Europe no parasites could be reared, and, though the moth has been in the NO. 2 I I 8 , vOL. 83 ]
United States for more than forty years, no American species is known to attack its eggs. "Non-parasitism of $P$. dispar by native species," writes Dr. Howard, "is probably due to the character of its egg-mass, which is so compact and so thoroughly protected by the scales of its parent as possibly to disguise its character from species unacquainted with it."

G. H. C.

ALTERATIONS OF THE DEVELOPMENT AND FORMS OF PLANTS AS A RESULT OF ENVIRONMENT.

THE fungus Saprolegnia is chosen as an example among the iower plants. This fungus lives on dead insects, and shows three distinct stages of its development:(I) vegetative growth of the mycelium; (2) asexual reproduction by motile zoospores; (3) sexual reproduction by male and female organs. Under ordinary conditions these three stages follow one another quite regularly until, after the ripening of the resting spores, the fungus dies; but, according to the special conditions of every stage, it is possible to produce them as we desire, and also to alter their succession. Under very favourable conditions of nutrition the fungus must continuously grow, without being propagating and without dying. Numerous other lower plants, as fungi and algæ, show the same relations to environment.

Flowering plants present far more difficulties, in consequence of their very complicated structure. Sempervivum Funckii is taken to show how far the development of such a plant depends on environment. Sempervivum appears as a short stem covered with thick sappy leaves; we call this form a rosette. The rosettes produce in an asexual way new daughter-rosettes, of which each comes to flower under suitable conditions, and dies after the ripening of seeds. The state of a plant, destined to flower but without recognisable rudiments, is called ripe to flower. The formation of the inflorescence consists of three essential stages:-(I) the lengthening of the stem; (2) the production of several branches at the top; (3) the birth of flowers.

Under very favourable conditions of nutrition, a rosette ripe to flower can be transformed again into a vegetative one, which must always grow without sexual reproduction. In blue light, during March and April, a lengthening of the rosette ripe to flower takes place, but without flowering. Such a lengthening of the stem is wholly independent of flowering, because all rosettes, also the youngest ones, are able to lengthen in red light. On the other hand, the flowers can resuit without lengthening when the rosettes are exposed to a high temperature. 'The production of flowering branches can be prevented, the inflorescence at the end having but a single flower. In other conditions numerous bianches are to be found on the whole stem, even in the axils of the old leaves, particularly as the result of injuries.

We come to a new series of forms by replacing flowers by leaf-rosettes, which can be produced on all parts of the inflorescence, even on the flowering branches, alone or mingled with flowers. The plants, of which the inflorescence bears rosettes, do not die at the end of summer as is normal, but live another two or more years, appearing in peculiar forms. It can be shown that flowers vary in an exceedingly high degree under certain conditions. The number and arrangement of all members as sepals, petals, stamens, and carpels can be altered. Further striking variations of the normal forms appear in such artificially modified flowers by the transformation of sepals into petals, of petals into stamens, of stamens into petais and into carpels. Experiments were made to answer the question whether alterations of flowers can be transmitted. For such researches Sempervivum acuminatum, which produces easily ripe seeds, was used. The seeds of flowers artificially altered and self-fertilised gave rise to twentyone seedlings, among which four showed surprising deviations in their flowers. With two seedlings all the flowers were greatly altered, and presented some of the alterations of the mother plant especially the transformation of stamens into petals. The experiments are being continued. 1 Abstract of the Cromian Lecture delivered at the Royal Society on May 26 by Prof. G. Klebs. 